\title{
Numerical simulation of the wind turbine erosion
}

\author{
Yarong Du, Weiwei Chen \\ NORTH CHINA ELECTRIC POWER UNIVERCITY ,Baoding
}

\begin{abstract}
Keywords: wind turbine, erosion, numerical simulation.
Abstract. In this article, through the numerical simulation of the wind turbine under different wind speed, we can observe the changes of the blade surface pressure. If the air pressure of the blade surface is larger, the erosion is more serious. In consequence the erosion degree will be more and more serious form the blade root to the tip, and the erosion is most serious at the tip of the wind turbine blades, which is ought to be equipped with protective coating.
\end{abstract}

\section{Introduction}

The wind turbine is a device, which can convert wind energy into mechanical energy .In order to solve the energy shortage, environment pollution global problem in the 21 st century, And utilize the renewable and clean wind energy better, the three-bladed horizontal axis wind turbine is used widely .During their operation life, wind turbines have been much eroded by the surrounding environment, which destroys the geometry structure of the blade surface, and changes the aerodynamic performance of blades. The factors mentioned above reduce the wind energy utilization coefficient and reduce the service life of the wind turbine .Therefore it is meaningful to research the wind turbine operation conditions under different wind speed. In this article, through the numerical simulation of the wind turbine under different wind speed, we can observe the changes of the blade surface pressure.

\section{The wind erosion mechanism}

In the wind turbine operation process, the air mixed with sand and water drops will cause serious erosion on blades. Because of the high rotating speed of blades (especially blade tips), a single tiny particles hit the blades in a few milliseconds, which produces very large impact. The burst of a water droplet on the blade surface causes large shear stress, And when there exist cracks, lateral jet shear stress will be larger. Because of the relative friction between tiny grains of sand with irregular shape and the blade surface, the blade wear is serious. In addition, sand particles and water droplets scour the blades continuously, which can produce lasting load on the surface. These reasons result in the loss of the blade surface fatigue strength and cause strong damage to the blade material. With continuous function of erosion, abrasion, surface fatigue, plastic deformation, brittle fracture in turn occur on the blade surface. The size and mass flow rate of sand particles and water droplets, air flow rate, vane length, vane surface materials and many other factors have a serious impact on the process of wind erosion. Because air velocity has effect on the impact speed of particles and the rotation speed of the wind turbine blades, and influencing the wind energy utilization coefficient of wind turbines, therefore we need to research on operation condition of blades under different wind speeds.

\section{The physical model}

Firstly draw the wind turbine blade model with Solidworks Software, whose length is about five 
meters and geometry is shown in Fig.1. Then assemble into the three-bladed wind turbine model shown in Fig. 2 .For the wind turbine model, the Flow simulation Software automatically generated cuboid wind field calculation domain which is from $-33 \mathrm{~m}$ to $55 \mathrm{~m}$ in the $\mathrm{x}$ direction, from $-38 \mathrm{~m}$ to $38 \mathrm{~m}$ in the $\mathrm{y}$ direction, and from $-38 \mathrm{~m}$ to $38 \mathrm{~m}$ in the $\mathrm{z}$ direction. We need to inject air at the $\mathrm{x}=-33 \mathrm{~m}$ plane and acceleration of gravity in the negative $\mathrm{Y}$ direction is $9.81 \mathrm{~m} / \mathrm{s} 2$. The blade wall is heat insulation and the roughness is 0 . The environmental pressure is $101325 \mathrm{~Pa}$ and temperature is $293.2 \mathrm{~K}$.

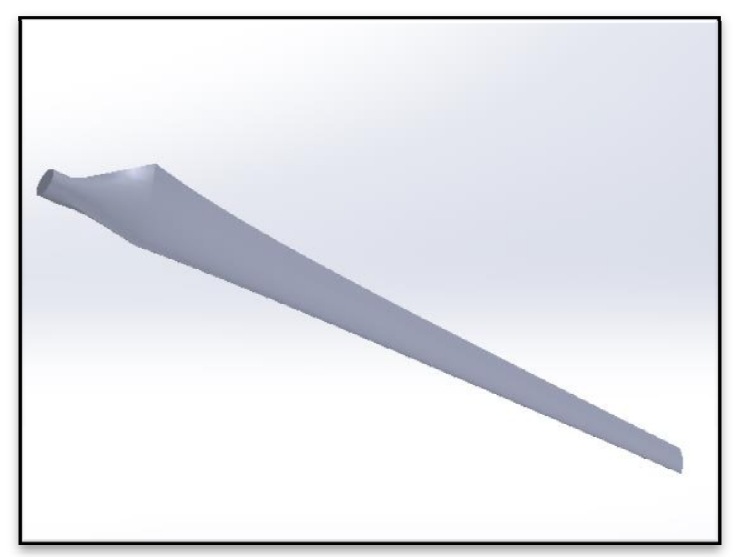

Fig.1 The blade model

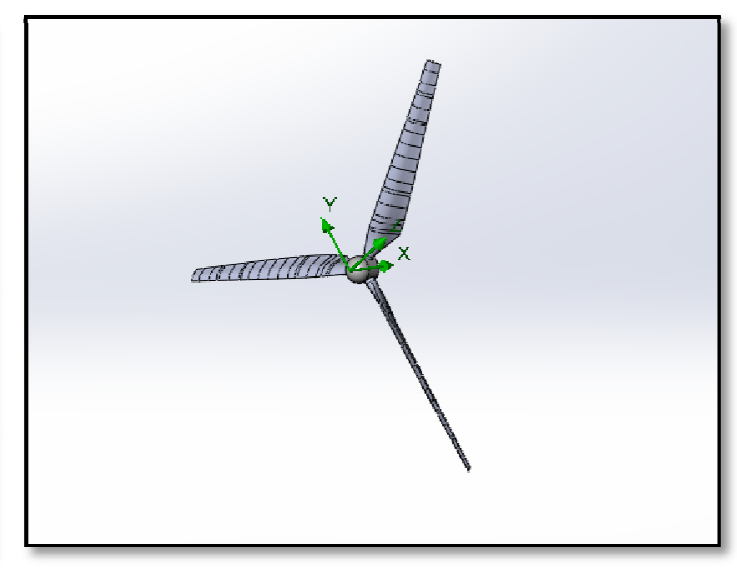

Fig.2 The wind turbine model

Build wind turbine wizard with the Flow simulation software, and enter the initial parameters and boundary conditions. The type of flow is the external flows and the inflow air velocity is $3 \mathrm{~m} / \mathrm{s}$ at the $x=-33 \mathrm{~m}$ plane. Wind turbines' angular velocity of rotation is calculated as $\omega=\frac{\lambda * V}{R}$, where $\lambda$ is the optimum tip speed ratio(generally three-blade wind turbines' optimum tip speed ratio is about 7), $\mathrm{V}$ is the air flow velocity, and $\mathrm{R}$ is the blade length of $5.0 \mathrm{M}$. Therefore the angular velocity of rotation is $4.2 \mathrm{rad} / \mathrm{s}$. The initial mesh precision is 4 , and the minimum wall thickness is set to $1 \mathrm{~m}$, which optimizes thin walls resolution. We need to insert global goals, point goals and surface goals as engineering goals, where the parameters to be solved are total pressure and velocity . After running the computer will automatically iteratively calculate, and the solution process will end in about 2 hours. Reset the air flow velocity, and respectively set the velocity into $5 \mathrm{~m} / \mathrm{s}, 7 \mathrm{~m} / \mathrm{s}, 9 \mathrm{~m} / \mathrm{s}, 11 \mathrm{~m} / \mathrm{s}, 13 \mathrm{~m} / \mathrm{s}, 15 \mathrm{~m} / \mathrm{s}$, correspondingly the angular velocities of rotation are 7 $\mathrm{rad} / \mathrm{s}, 9.8 \mathrm{rad} / \mathrm{s}, 12.6 \mathrm{rad} / \mathrm{s}, 15.4 \mathrm{rad} / \mathrm{s}, 18.2 \mathrm{rad} / \mathrm{s}, 21 \mathrm{rad} / \mathrm{s}$. Other conditions remain unchanged.

\section{The calculation results}

Insert the surface plots in the Folw Simulation analysis tree, then get the wind turbine blade surface pressure distribution. The results are shown in Figure 3-9. For a visual comparison, insert total pressure as point parameter in the Folw Simulation analysis tree. According to symmetry, we need only to study on pressure distribution of a blade, and the point positions are shown in Fig. 10. 


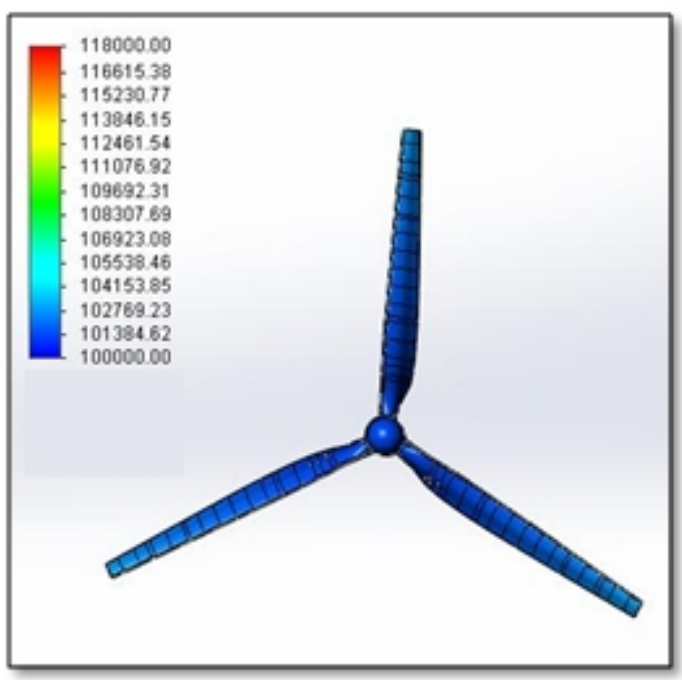

Fig. 3 surface plot under the flow rate of $3 \mathrm{~m} / \mathrm{s}$

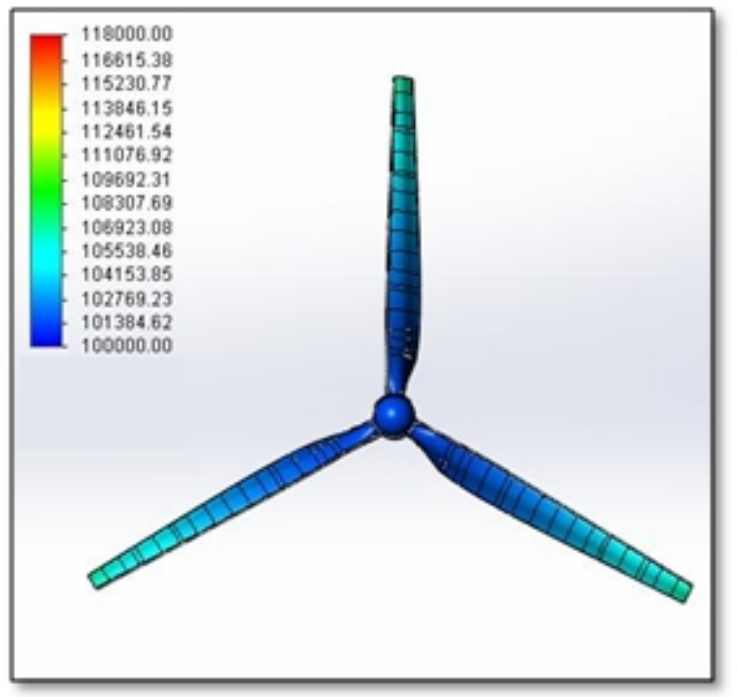

Fig. 5 surface plot under the flow rate of $7 \mathrm{~m} / \mathrm{s}$

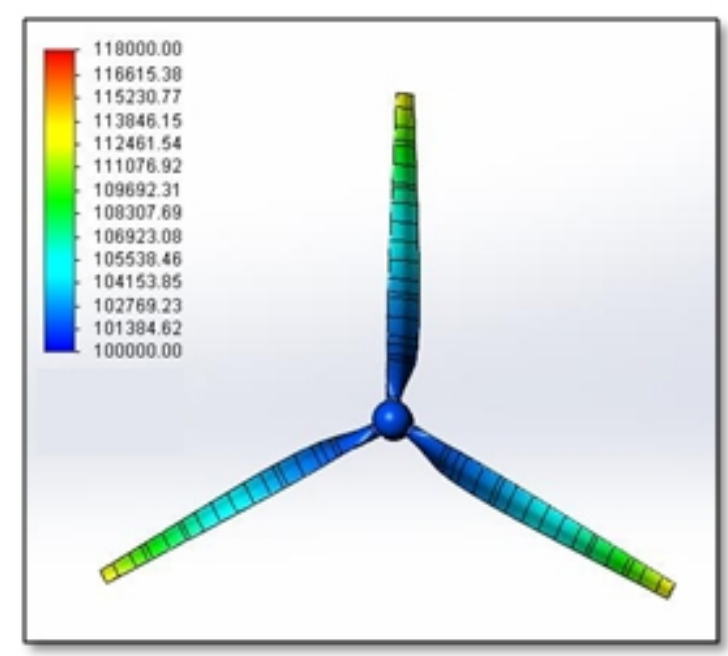

Fig. 7 surface plot under the flow rate of $11 \mathrm{~m} / \mathrm{s}$

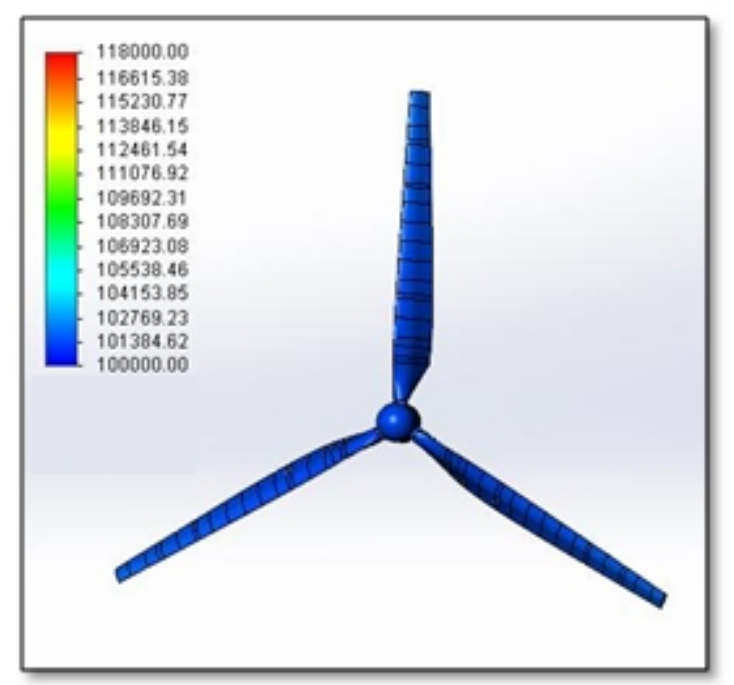

Fig. 4 surface plot under the flow rate of $5 \mathrm{~m} / \mathrm{s}$

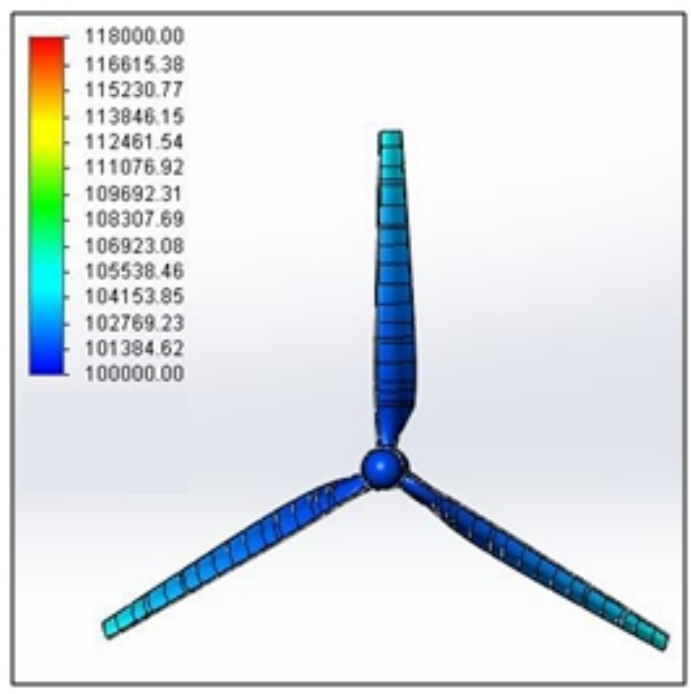

Fig.6surface plot under the flow rate of $9 \mathrm{~m} / \mathrm{s}$

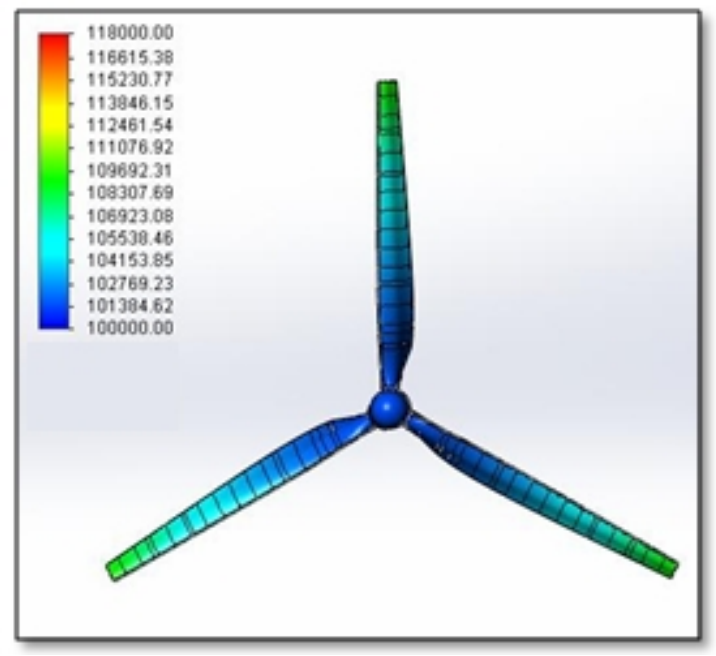

Fig. 8 surface plot under the flow rate of $13 \mathrm{~m} / \mathrm{s}$ 


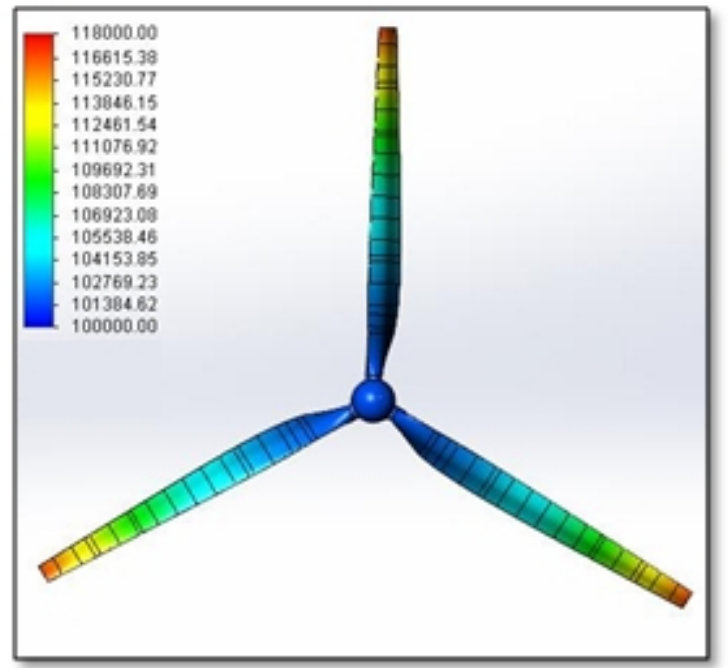

Fig. 9 surface plot under the flow rate of $3 \mathrm{~m} / \mathrm{s}$

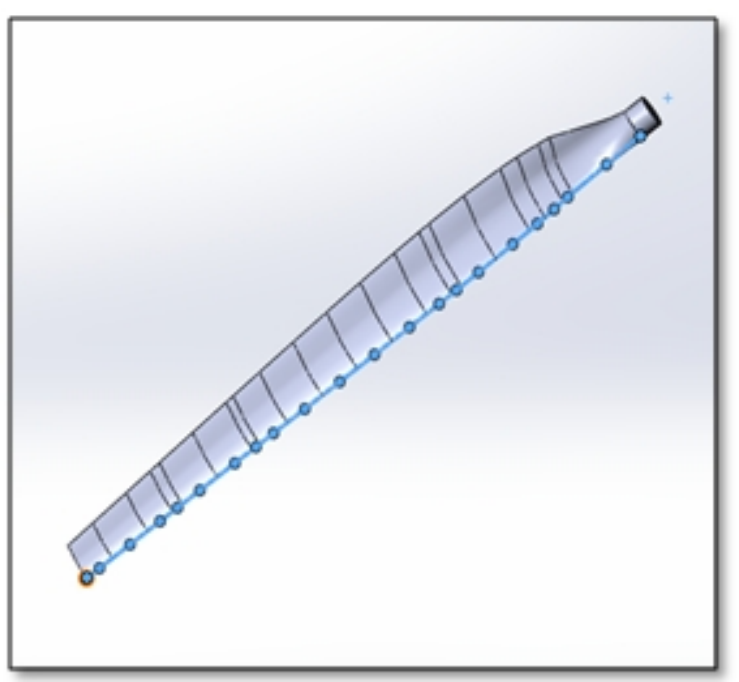

Fig. 10 the point positions

Get the parameters under different air flow speeds, and then these parameters will be drawn into the line chart as shown in figure 11.

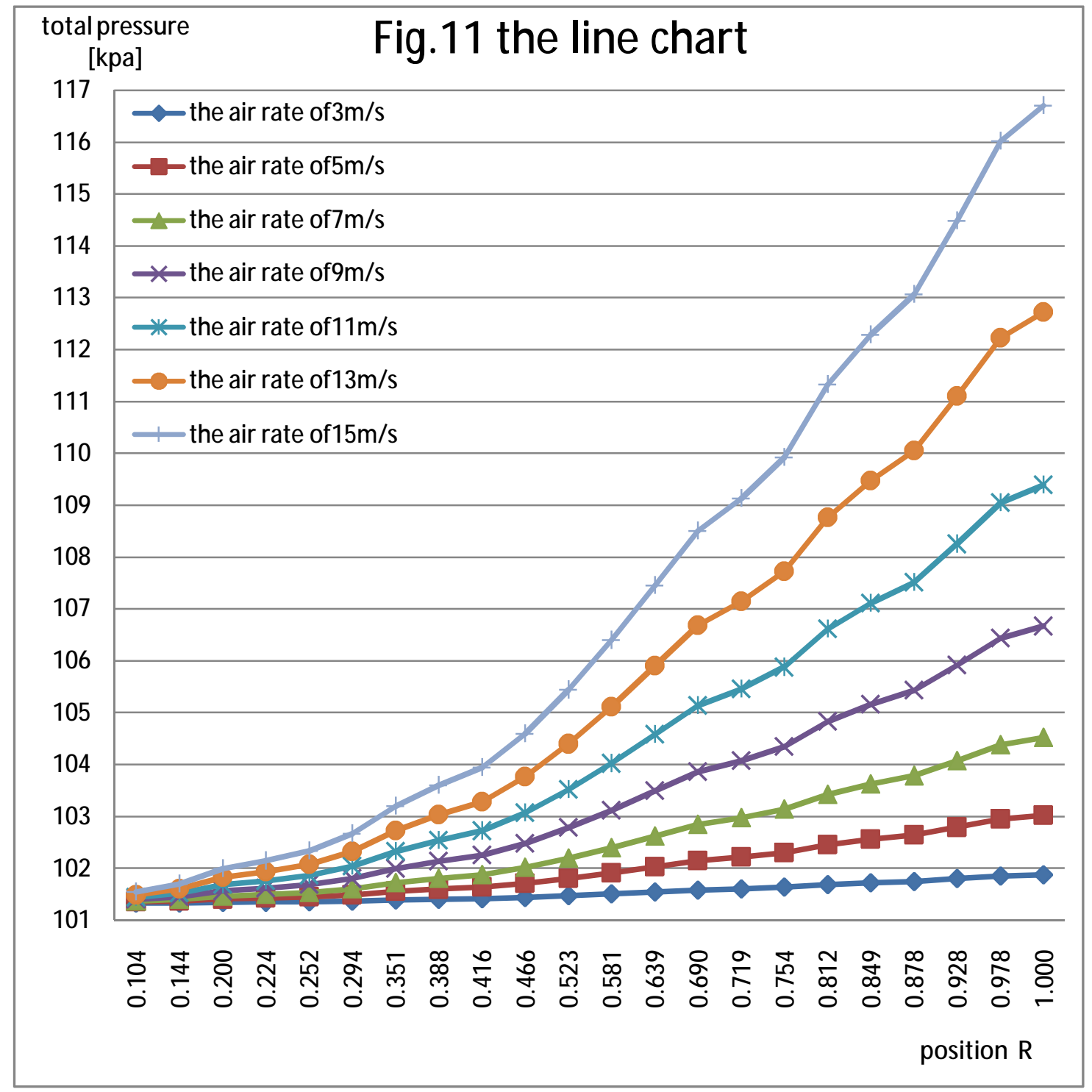




\section{Conclusion}

Based on the above analysis, we can see that under the same air velocity, the pressures of the blades surface from the blade root to tip increase, and the increase amplitude is affected by the air flow, which the faster air flows, the greater the amplitude of pressure increases. And the bigger the air flow velocity is, the larger the pressure is on the same position of blades. If the air pressure of the blade surface is larger, the erosion is more serious. In consequence the erosion degree will be more and more serious form the blade root to the tip, and the erosion is most serious at the tip of the wind turbine blades, which is ought to be equipped with protective coating. Although there exist ideal conditions for numerical simulation, such as wall smooth, temperature, pressure, etc, the results have reference significance for us to realizing the flow characteristics of the wind turbine and the relationship between pressure of blade surface and velocity of air

\section{Reference}

[1] J Liersch ,J Michael.Investigation of the impact of rain and particle erosion on rotor blade aerodynamics with an erosion test facility to enhancing the rotor blade performance and durability.The Science of Making Torque from Wind.(2014)

[2] Chen Chaoxiang,Ye Xiuzi. Flow Simulation Course. China Machine Press.(2011)

[3] Li Xinyi,Qi Wenjun. Numerical simulation of horizontal wind turbine blade in the sand-flow field. Urumqi: School of Mechanical Engineering,Xinjiang University.(2014)

[4] Wang Jingjing,Zhao Xu,Ye Chen. Numerical Simulation of Small Horizontal-Axis Wind Turbine Rotor. Xi'an: Northwestern Polytechnical University.(2013)

[5] Sui Jianhua.Numerical Simulation Studies of Horizontal Axis Wind Turbines.Harbin: Harbin Engineering University.(2011)

[6] Khandakar Niaz Morshed, Mosfequr Rahman, Gustavo Molina ,Mahbub Ahmed.Wind tunnel testing and numerical simulation on aerodynamic performance of a three-bladed Savonius wind turbine .International Journal of Energy and Environmental Engigeering.(2013)

[7] Zhang Renliang.3-D Modeling and Simulation Analysis of Wind Turbine Blades Based on SolidWorks.Xiangtan City:Xiangtan University.(2012)

[8] Wang Jian-Wen,Jia Rui-Bo,Wu Ke-Qi. Numerical Simulation on Effects of Pressure Distribution of Wind Turbine Blade with a Tip Vane . Journal of Thermal Science.(2007)

[9] Dong Lin.Research on gas-solid aerodynamic characteristics of wind turbine airfoil under the sand-wind environment.Lanzhou City:Lanzhou University of Technology.(2014)

\section{Acknowledgements}

This work is supported by the fundamental research funds for the central universities. 